\title{
Design of the automation of hybrid system of forced natural ventilation from buried pipes and of air conditioning for interior spaces in a tropical zone
}

\author{
C. Arias ${ }^{1}$, G. Osma ${ }^{1}$, G. Ordóñez ${ }^{1}$ \\ ${ }^{1}$ School of Electrical, Electronics and Telecommunications Engineering \\ Industrial University of Santander \\ Carrera 27 Calle 9, 68001000, Bucaramanga, Colombia \\ Phone: +57 7634 4000, e-mail: carias8709@gmail.com, german.osma@gmail.com
}

\begin{abstract}
This paper shows the design of the automation of a hybrid system of the forced natural ventilation from buried pipes and of the air conditioning for interior spaces, according climate condition of the city Bucaramanga. Such design is based in a study about the thermal needs of an interior space in a building of the Industrial University of Santander. The design consists in the selection of protocol and the components and in the development of an interface for viewing of the performance of the system.
\end{abstract}

\section{Keywords}

Automation, buried pipes, natural ventilation, rational use of energy.

\section{Introduction}

Nowadays, buildings consume between $30 \%$ and $50 \%$ of the energy worldwide, and for that they cause significantly emissions of $\mathrm{CO}_{2}$. This energy demand is mainly due to mechanical systems for attending the thermal comfort.

The reduction of such consumption can be achieved from of the use of natural ventilation. Now, taking into account that the ambient temperature in the tropical zone is above of the acceptable value for comfort thermal (e.g. $26^{\circ} \mathrm{C}$ ) part of the time, it is considered appropriate to undertake and to implement hybrid strategies of forced natural ventilation and air conditioning.

For achieving the expected reduction of the energy consumption and ensuring comfort conditions for the users, it is proposed in this work an automation strategy for the operation of a system of forced natural ventilation from buried pipes and an air conditioning system.

This work was done in the campus of the Industrial University of Santander, since a process of strengthening of the physical infrastructure is being carried out, especially buildings. It is framed in the strategic plan of sustainability of the university, which has as a pillar the integration of the energy applications.
In the section II were established the technical characteristics of the system of ventilation for climate and geographic conditions of Bucaramanga. The section III is shown the automation system, mainly the selection of the protocol and components (sensors and actuators). In the section IV is presented the interface for automating the performance of the system. Finally, the results and conclusions are described.

\section{Considerations about the buried piped system}

In this section is described the operating and performance of the system of buried pipes systems; also, it is shown the sizing of the system, in accordance with the weather conditions and the soil characteristics of the Industrial University of Santander.

\section{A. Operating principle}

According to [1], the buried pipes system is an open-loop strategy, also known as EAHX (Earth-air heat exchanger) [2] o GHE (Ground heat exchanger) [3], [4]. This technology is classified as zero emissions [2], [3], [5].

Its operating principle consists in the use of the difference between the air temperature to ambient condition and the soil temperature around of the building, according to the depth [1]. The air is heated or cooled when driving for the pipes, due to the heat exchange with the soil, which acts as a large thermal reservoir [6], [7].

These systems allow the creation of micro-climates to the interior of buildings [8]. According to [1], [9] and [10], they have a lifetime of until 50 years and can generate savings between $30 \%$ and $100 \%$. Their use is increased in modern buildings from 1990, mainly in Europe [6].

In this system the air circulates from outside towards the inside of the buildings through of buried pipes to specific speed. The movement of the air is forced by an electrical injector [2]. 
The aspects more relevant for taking into account in the design are the diameter and length of the pipeline, the depth of installation and the air speed [1].

The diameter of pipes must be selected according to a balance between heat transfer and the air speed, since they are opposite aspects. The speed and the diameter determine the electrical power of the injector.

The length and the depth of the installation determine in most of the level of heat transfer [1]. There is greater heat transfer when the length of pipeline is increased [2].

The regions located in the tropical zone often have air very humid; this influences the soil characteristics. The wet soils are preferred due to a greater thermal conductivity.

\section{B. Site conditions}

The identification of the kind of the soil in the university was made based on the information shown in [11] and [12]. It was concluded that the kind soil in the campus is red slime and the thermal conductivity is $1,5 \mathrm{~W} / \mathrm{m} \cdot \mathrm{K}$.

The measurements of the soil temperature were done for three depths, $1 \mathrm{~m}, 2 \mathrm{~m}$ and $3 \mathrm{~m}$ in a space near to the building, during three months with data collection every hour, from 6 a.m. to 8 p.m. It was used RTD PT100 class A. The results are shown in the Fig. 1. From this information, it is possible to indicate that this technology has potential for its application in Bucaramanga. Based on the measurements made, it was established that the appropriated depth for developing the application is $3 \mathrm{~m}$. In addition, these measurements were compared with the model of Baehr-Stephan [14] as is presented in the Fig. 2.

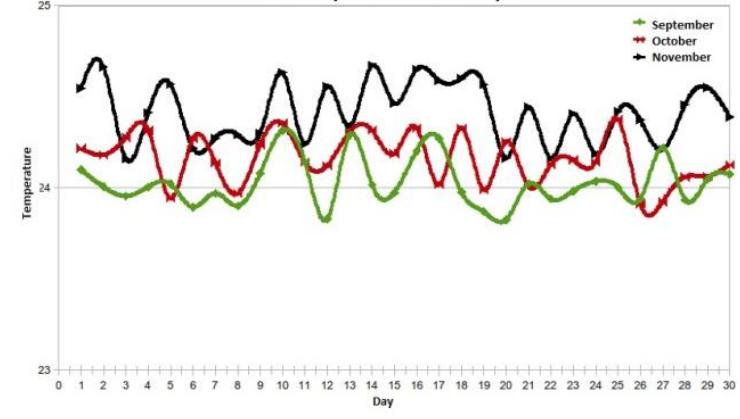

Fig 1. Temperature of the soil to $3 \mathrm{~m}$ of depth.

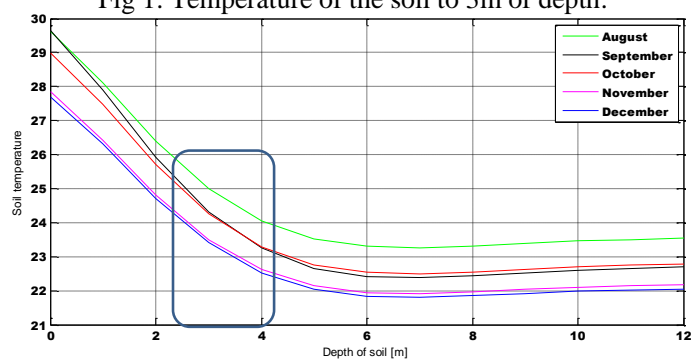

Fig 2. Soil temperature by Baehr-Stephan model.

On the other hand, Bucaramanga has a warm wet climate, with an average temperature that varies mostly between $20^{\circ} \mathrm{C}$ and $27^{\circ} \mathrm{C}$, where the $75 \%$ of the time the temperature is below of $26^{\circ} \mathrm{C}$.

\section{Projecting}

The sizing of the system was made for an inside space of $250 \mathrm{~m}^{2}$, with 6 renovations per hour, and where the pipes must be installed to $3 \mathrm{~m}$ of depth. The thermal conductivity is $1.5 \mathrm{~W} / \mathrm{mK}$. The maximum acceptable temperature in the final point of the pipeline is $26^{\circ} \mathrm{C}$.

The design of the system is based in the approach of semiinfinite solid by [13], which idealizes the heat transfer in proximity of the surface; also, in Baehr-Stephan [14], which proposes that the temperature in the surface $\left(T_{\text {sup }}\right)$ during the year follows the behaviour indicated by the expression (1). This depends of the annual average temperature $\left(T_{a}\right)$, the annual maximum temperature $\left(T_{\max }\right)$, the time $(t)$ and the duration of the year $\left(t_{o}\right)$.

$$
T_{\text {sup }}(t)=T_{a}+\left(T_{\max }-T_{a}\right) \cos \left(2 \pi \frac{t}{t_{0}}\right)\left[{ }^{\circ} C\right]
$$

In [14] is proposed a solution for the variation of the temperature of the soil $(T(x, t))$ in function of the depth $(x)$ and the time $(t)$, which is shown in (2); where the constant $m$ is calculated by (3) and $\alpha\left[\mathrm{m}^{2} \cdot \mathrm{seg}\right]$ is the thermal diffusivity.

$$
\begin{gathered}
T(x, t)=T_{a}+\left(T_{\max }-T_{a}\right) e^{-m x} \cos (2 \pi-m x) \\
m=\sqrt{\frac{\pi}{\alpha t_{0}}}
\end{gathered}
$$

For the study of heat transfer that occurs in a system of earth-air heat exchanger is considered the model of Benkert, Hedidt and Schöler [15].

The ambient air temperature determines the temperature of input of the exchanger and it is the boundary condition of the proposed solution by Baehr-Stephan [14].

For establishing the length of pipeline, the analysis of the heat exchanger was done by section of pipeline (e.g. $3 \mathrm{~m}$ ), which determined the variation of air temperature by section. The length of pipeline is calculated by the number of the sections that allow achieving the expected temperature of air. It was selected a section pipe of $6 \mathrm{~m}$ length and $15.2 \mathrm{~cm}$ of diameter.

The radius of heat transfer (B) depends on some input data, such as thermal conductivity of the soil at the site of $k_{S}$ installation, installation depth $S_{0}$ and tube radius $R_{0}$. This is calculated taking into account the thermal conductivity of air in the tube $K_{a}$ Nusselt number $(\mathrm{Nu})$ of the air in the tube. For that, is used the model of Benkert, Hedidt and Scholer, which represents the heat transfer between the surface of the ground, the tube and the air flow inside of the tube. Moreover, depends on the coefficient of heat transfer along the tube wall.

However, it is necessary to calculate the temperature of the soil in the tube wall called $T_{(E, 0)}$ (soil temperature at the depth of installation), taking account that the maximum temperature is $24.63{ }^{\circ} \mathrm{C}$ for $t=0$. 
Subsequently, the temperature of the inlet air tube $T_{(A, P)}$ must be estimated. Initially is taken the highest annual temperature averaged in $29.4^{\circ} \mathrm{C}$. For being consistent with that the temperature of the earth on the wall of the tube $T_{(E, W)}$ is calculated.

$$
\begin{gathered}
Q_{w} \cdot=\Delta_{z} U_{L}\left(T_{(E, W)}-T_{(A, P)}\right)(4) \\
Q_{w} \cdot \dot{m} c_{p}\left(T_{(A, P) \text { out }}-T_{(A, P) \text { in }}\right)(5)
\end{gathered}
$$

Finally, to find the initial conditions of temperature $T_{(A, P)}$ and $T_{(E, W)}$ to the input of the next segment of heat balance between $\left(\dot{Q_{w}}\right)(4)$ and $\left(\dot{Q_{w}}\right)(5)$ is performed. In Equation 5 will have the difference between the air temperature at the inlet section and the air temperature at the outlet thereof, so provided that the air temperature at the exit of the section is the air temperature the input of the next stage. This is iterated until the target outlet air temperature.

Based in the use of the model, some curves were established. In the Figure 3 is shown the relation between renovation and length of pipeline, to higher percentage of renovation is required more length for achieved the same temperature at the ending of pipeline.

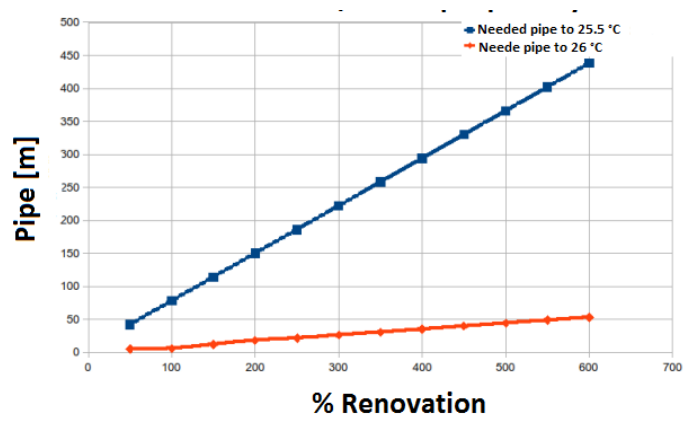

Fig 3. Percentage of Renovation vs. length of pipeline.

The simulation result indicates that to meet the requirement of 6 air changes per hour and get the target temperature of $25.5^{\circ} \mathrm{C}$ the installation of 10 pipe parallel sections each one with 45 meters installed to 3 meters of depth.

\section{Thermal load of the building}

To determine the heat load of the internal space, it was developed an application in Visual Basic 6.0 that considers the number of people in the room, walls exposed to solar radiation, electrical equipment, lighting and size of accommodation, among others. It was determined that it requires the use of four air conditioning units $24 \mathrm{kBTU}$ or 3 units of $36 \mathrm{kBTU}$.

\section{System Design}

The system designed is based on the characteristics of a building automation system, which seeks to satisfy the needs of users. This is achieved in part by controlling the indoor conditions.

For the case of the specific application of this work, it is necessary to determine the communication protocol, sensors, actuators, and controllers.

\section{A. Hybrid system operation}

Initially, there is a presence detector which indicates the start of the operation of the hybrid system.

Buried pipe system consists of an axial fan with the aim of push air from outside to inside of the pipes and at the end of them there is a damper that opens simultaneously with the windows. It is very important that the damper detector and windows are in open state before operating the fan impeller.

At the same time that is enable the buried pipe system, a timer will start to count five minutes as a waiting time to satisfy primary conditions. After this, it is verify the limit of comfort temperature, if not achieved, will be ordered to close windows and damper, and to turn off the axial fan, immediately is enabled the air conditioning.

Accordingly, the air conditioning will operate until establish and attend the set point of comfort temperature. If there is not any presence of people, so the system simply turns off. In the Figure 4 is shown the general scheme of the system.

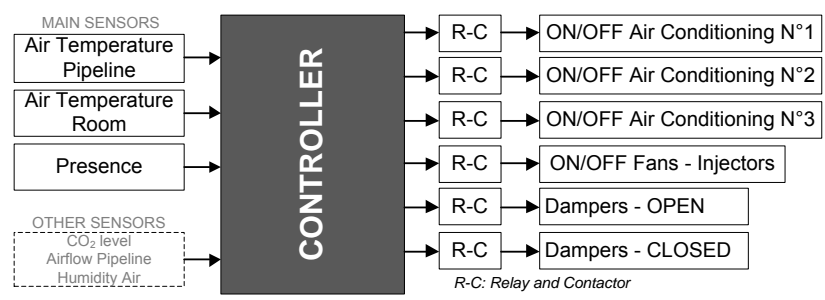

Fig 4. Scheme of system.

\section{B. Selection of the communication protocol}

The communication protocol is the language that allows the sending and/or receiving data from one place to another one, for the interconnection between two or more devices.

The comparison included 6 options due to the available the building automation protocol in Colombia, which are LonWorks, KNX, X-10, MODBUS/TCP, OPC, TCP/IP.

The tool selected for this task was the AHP methodology (Analytic Hierarchy Process), which is a multi-criteria process designed to quantify judgments about the relative importance of each of the conflicting criteria used in the decision making process to be used.

The selection criteria were adaptability, accessibility, cost and technical characteristics. Adaptability refers to the ability to quickly and easily accommodate various functions, specifically the management of lighting and air conditioning. Accessibility treats about the access the university to this technology. The cost relates the financial value involved in choosing this tool. Finally, the technical characteristics allow assessing the operation of the protocol. As result of this process was established that the most suitable protocol is MODBUS / TCP, as shown in Table I, which presents other options. 
TABLE I. AHP Methodology results.

\begin{tabular}{|c|c|c|}
\hline PROTOCOL & TOTAL & POSITION \\
\hline MODBUS/TCP & 0,970 & 1 \\
\hline OPC & 0,939 & 2 \\
\hline LONWORKS & 0,927 & 3 \\
\hline
\end{tabular}

\section{Sensors}

Sensors are devices capable of converting physical, chemical and biological signals to electrical signals. It provides the desired information to a controller. Table II presents the selected sensors to be implemented and compare to other devices.

TABLE II. Sensors of the system.

\begin{tabular}{|c|c|}
\hline Air pipe temperature & $\begin{array}{c}\text { RTD PT100 Tipo A, con } \\
\text { transmisor pyromation TM01-440 }\end{array}$ \\
\hline $\begin{array}{c}\text { Air temperatura inside } \\
\text { the room }\end{array}$ & PCE-EE22-Temperature sensor \\
\hline Humidity & PCE-EE22-Humidity sensor \\
\hline Air flow & Rotameter PCE-EE-65 \\
\hline $\mathrm{CO}_{2}$ detector & MOL-CO 2 -3-10V \\
\hline Presence detector & ODC0S-11W \\
\hline
\end{tabular}

\section{Actuators}

The most actuators used in inmotic systems are relays and contactors, allowing high power switching circuits with low power signals, as air injectors and air conditioners.

Actuators on-off type are used to operate the windows and the buried pipe system, in order to allow airflow of natural ventilation or prevent loss when operating the air conditioner.

\section{E. Controller}

The controllers are devices for including the algorithms in a specific programming language. It is responsible for sending signals to the actuators. The selection of the controller depends of the needs and the associated cost. PC's, microcontrollers, PLC's, PAC (programmable automation controllers) can be used as controllers for building automation systems.

\section{MHI-Machine Human Interface}

For the design of the interface is necessary to use the SART model, it has different levels which allows to describe the behaviour of an automation system. SART model appeared in 1978 and was proposed by De Marco and Yourdon. At the main level are shown all endpoints such as temperature sensors, the air conditioning system and injectors of the system. The data flow can be continuous or discrete.

The second level identifies the process to be carried out internally, as control signals, data storage, and activation of the control actions; as shown in Fig 5.

For the third level and next, it is possible to resort to a flowchart or state machine PSPEC.

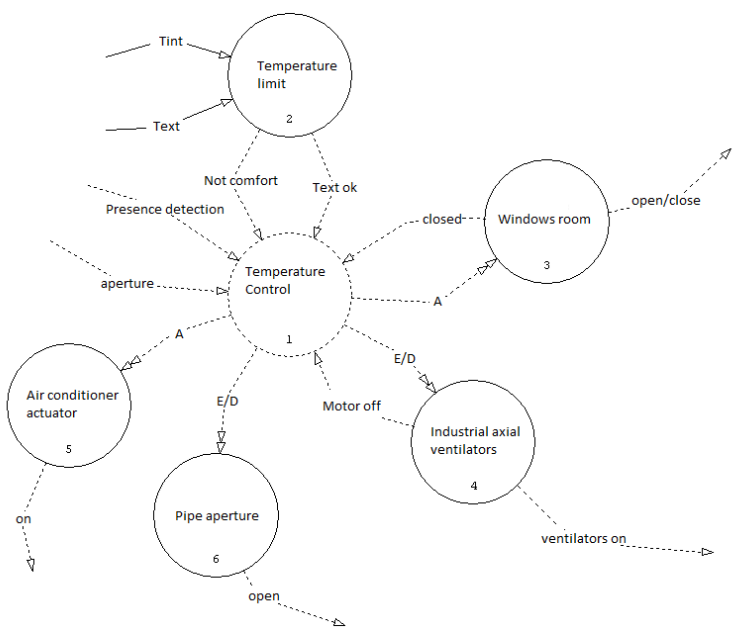

Fig 5. SART modelling second level.

These levels give detailed information on the sequence as execute the various tasks of the system.In Fig 6 is shown the state machine to control both processes proposed in the system.

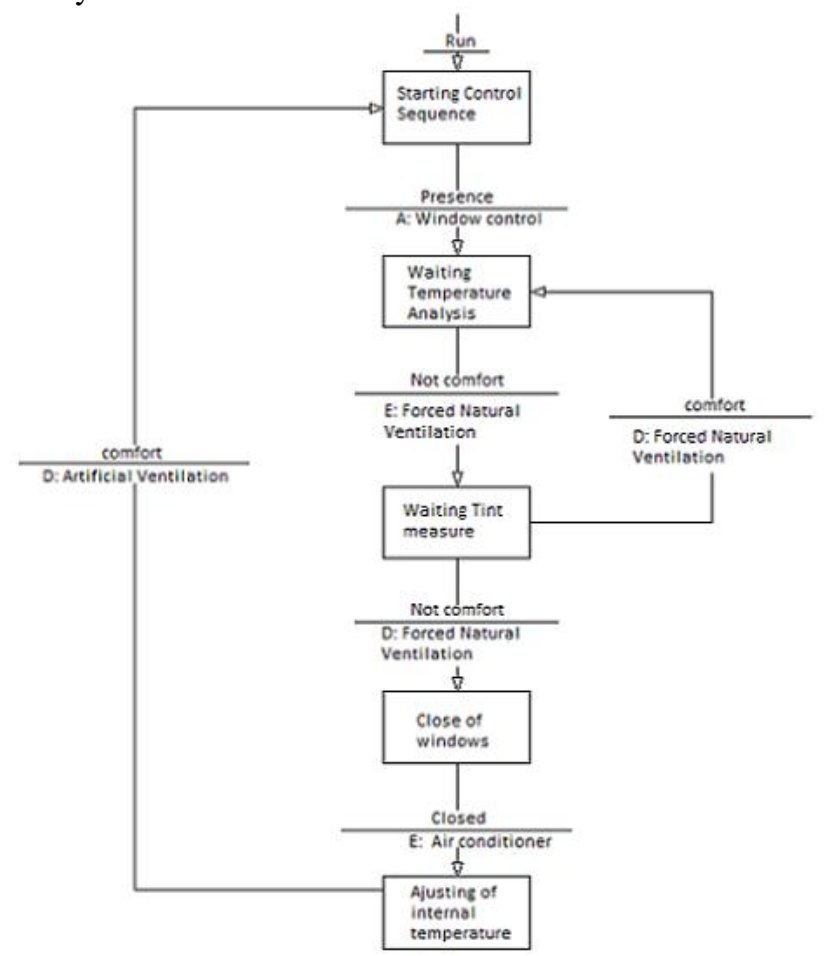

Fig 6. State Machine.

The interface was developed in LabVIEW, because this is a graphical programming language for the design of data acquisition systems, instrumentation and control. It has an interactive console and features easy integration with hardware, specifically measuring cards, data acquisition and processing (including imaging).

The Figure 7 shows the display of each of the sensors and actuators necessary for supervising the entire control ventilation, such as three temperature sensors (outside ambient temperature, temperature in the tube wall and the room temperature), which employ configurations transmitters output between $4 \mathrm{~mA}$ and $20 \mathrm{~mA}$. 


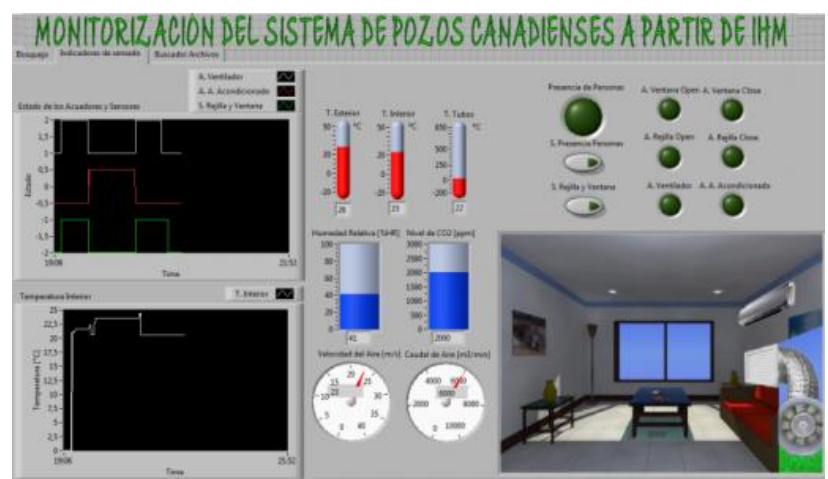

Fig 7. Tab of animations at the forced natural ventilation system.

\section{Results, conclusions and recommen- dations}

For the design of the automation and control of natural ventilation forced from buried pipes, several variables were established from analysis of a surface-to-air exchanger, measurements in situ and adapting to climatic behaviour of Bucaramanga.

Measurements of soil temperature were made at different depths, $1 \mathrm{~m}, 2 \mathrm{~m}$ and $3 \mathrm{~m}$. RTD is used for greater reliability.

It was established that to meet the requirement of 6 air changes per hour and a temperature comfort limit of $25.5^{\circ} \mathrm{C}$ in an area of $250 \mathrm{~m}^{2}$, the installation of 10 pipe sections of $45 \mathrm{~m}$ each is required, with a diameter of pipe of $15.2 \mathrm{~cm}$ and each pipe length of $6 \mathrm{~m}$.

In order to achieve an architectural integration of scavenging air nozzles with the environment, there should be an additional utility, such as building benches for pedestrians. This helps ensure that the air will be taken in the shade.

The communication protocol should be standard because it takes a great variety in terms of addressing all devices deployed systems.

The protocol selection made from the Analytic Hierarchy Process (AHP) to four criteria: adaptability, accessibility, cost and technical characteristics. The protocols considered were: MODBUS/TCP, LONWORKS, TCP/IP, KNX, PROFIBUS, BACnet, CEBus, X -10, Zigbee and OPC. The selected protocol is MODBUS.

The selection of devices for building automation system depends directly on the drivers or selected control unit for compatibility criteria of protocols and technologies. In the selection of system devices was considered sizing and specifications.

The devices are analogue sensors and actuators ON / OFF, to avoid managing separate networks for each subsystem, that in order to reduce costs. In this design is established a basic automation level may be increased through the use of additional devices and equipment that provides automation market for that purpose.
It was designed a control algorithm not depending on the hours of use of the site, in order to simplify the automation and promote financial cost.

An automation system should seek simplicity in design helps to reduce the use of software and hardware resources, which favours functional and financial components.

An interface was developed to operate the automation system from exhaust drive, air conditioning and grid and the state of actuators and sensors. They allow monitoring of ambient room temperature, external temperature, temperature of the ground to the proximity of the tubes relative humidity, $\mathrm{CO}_{2}$ level in the enclosure, the air velocity inside the pipe. Performs data storage variables

An HMI makes the job more efficient, as it shows the real-time operation from an animation of the components. It must also be simple, intuitive and friendly to users.

The enclosure heat load was estimated from the method of Fanger, for which was developed a simple application in Visual Basic. Heat sources considered were: inner space occupants, artificial lighting and solar radiation transmitted by walls and windows, among others. Based on the thermal load is determined required number of renewals.

Due to varying climatic conditions in Colombia, it is necessary to previously carry out field measurements.

\section{References}

[1] Osma, Germán. Uso racional de la energía a partir del diseño de aplicaciones sostenibles en el Edificio Eléctrica II de la Universidad Industrial de Santander. Master Project. Industrial University of Santander. 2011.

[2] Ahmed, Abdullahi. Ip Kenneth. Miller, Andrew. Gidado, Kassim. Thermal performance of earth-air heat exchanger for reducing cooling energy demand of office buildings in the United Kingdom. Glasgow : 11th International IBPSA Conference. Building Simulation 2009, 2009. págs. 2228 2235.

[3] Demir, Hakan. Koyun, Ahmet. Temir, Galip. Heat transfer of horizontal parallel pipe ground heat exchanger and experimental verification. s.l. : ELSEVIER. Applied Thermal Engineering, 2009. págs. 224-233. Vol. 29.

[4] Koyun, Ahmet. Demir, Hakan. Torun, Zakir. Experimental study of heat transfer of buried finned pipe for ground source heat pump applications. s.l. : ELSEVIER. International Communication in Heat and Mass Transfer, 2009. págs. 739-743. Vol. 36.

[5] Hollmuller, Pierre. Lachal, Bernard. Buried piepe systems with sensible and latent heat exchange: Validation of numerical simulation against analytical solution and longterm monitoring. Montreal : 9th Conference of International Building Performance Simulation Association. August 2005, 2005. págs. 1-8.

[6] Mihalakakou, G. Santamouris, M. Asimakopoulos, D. Tselepidaki, I. Parametric prediction of the buried pipes cooling potential for passive cooling applications. s.l. : Pergamon. Solar Energy, 1995. págs. 163-173. Vol. 55.

[7] Costa, V.A.F. Thermodynamic analysis of building heating or cooling using the soil as heat reservoir. s.l. : ELSEVIER. Heat and mass transfer, 2006. págs. 41524160. Vol. 49. 
[8] Kabashnikov, V.P. Danilevskii, L.N. Nekrasov, V.P. Vityaz, I.P. Analytical and numerical investigation of the characteristics of a soil heat exchanger for ventilation systems. s.l. : Pergamon. Heat and mass transfer, 2002. págs. 2407-2418. Vol. 45.

[9] Musskopf, Diego. Sattler, Miguel. Natural Ventilation through buried pipes in a small school in Viamao (Brazil). s.1. : PLEA2006-23th Conference on Passive and Low Energy Architecture, Geneva, Switzerland, September 2006, 2006. págs. 1-6.

[10] Hollmuller, Pierre. Lachal, Bernard. Cooling and preheating with buried pipes systems: monitoring, simulation and economic aspects. s.l.: ELSEVIER. Energy and Buildings, 2001. págs. 509-518. Vol. 33.

[11] F.R. Gómez. Caracterización Dinámica de los suelos del campus de la Universidad Industrial de Santander sede Bucaramanga - Colombia, volume 1. Universidad Industrial de Santander, Tesis - Escuela de ingeniería Civil, 1a edition, 2007.

[12] M. Hermelín. Entorno natural de 17 ciudades de Colombia. Fondo Editorial Universidad EAFIT, 2007.

[13] F.P. Incropera and D.P. DeWitt. Fundamentos de transferencia de calor. Prentice Hall, 1999.

[14] St. Benkert, F.D. Heidt, D. Schöler. Calculation Tool for earth Heat Exchanges GAEA. University of Siegen. Germany.

[15] Karl Stephan Hans Dieter Baehr. Wärme-und Stoffübertragung (Transferencia de calor y masa). Springer-Verlag Berlin Heidelberg, 1994. 